\title{
Características Fisiológicas de Biótipos de Conyza bonariensis Resistentes aO Glyphosate Cultivados sob Competição ${ }^{1}$
}

\author{
Physiological Characteristics of Conyza bonariensis Biotypes Resistant to Glyphosate \\ Cultivated under Competition
}

GALON, L. ${ }^{2}$, FERREIRA, E.A. ${ }^{3}$, CONCENÇO, G. ${ }^{4}$, SILVA, A.A. ${ }^{5}$, SILVA, D.V..$^{5}$, SILVA, A.F. ${ }^{6}$, ASPIAZÚ, I. ${ }^{7}$ e VARGAS, L. ${ }^{8}$

\begin{abstract}
RESUMO - A resistência de plantas daninhas a herbicidas está relacionada a modificações metabólicas, enzimáticas, fisiológicas e/ou anatômicas. Aliado a essas mudanças, a planta pode aumentar ou diminuir as atividades fisiológicas, o que, consequentemente, pode afetar o seu crescimento e desenvolvimento. Assim, biótipos resistentes podem apresentar melhor adaptação ecológica em ambientes de cultivo e tornar-se predominantes devido à eliminação das plantas sensíveis. Em condições de seleção natural, biótipos com maior adaptação ecológica apresentam maior produção que biótipos menos adaptados. Neste trabalho, avaliou-se o efeito da competição em características fisiológicas de biótipos de Conyza bonariensis suscetiveis e resistentes ao herbicida glyphosate. Os tratamentos constaram de plantas de dois biótipos de $C$. bonariensis - um comprovadamente resistente e um suscetivel ao glyphosate, dispostas em modelo aditivo de estudo de competição. No centro da unidade experimental foram semeadas três sementes do biótipo considerado como o tratamento: resistente (R) ou suscetivel (S), sendo essa planta rodeada por 0 (testemunha sem competição), $1,2,3,4$, ou 5 plantas do biótipo oposto. O biótipo suscetivel apresentou-se mais tolerante à competição com plantas do biótipo oposto no tocante às características fisiológicas avaliadas. O biótipo resistente de buva apresenta desvantagem fisiológica em relação ao suscetivel e, consequentemente, menor potencial de adaptabilidade na ausência do fator de seleção - o herbicida glyphosate.
\end{abstract}

Palavras-chave: fotossíntese, transpiração, resistência, adaptabilidade ecológica.

\begin{abstract}
The resistance of weeds to herbicides is related to metabolic, enzymatic, physiological and anatomical changes. Coupled with these changes, plants can increase or decrease their physiological activities, which can affect their growth and development. Thus, resistant biotypes may have a higher ecological adaptation in these environments and become predominant due to the elimination of sensitive plants. Under natural selection conditions, biotypes with greater ecological adaptation show higher production than less adapted biotypes. Thus, the aim of this work was to assess the effect of competition on the physiological characteristics of Conyza bonariensis biotypes susceptible and resistant to the herbicide glyphosate. The treatments consisted of plants of two biotypes of $\mathbf{C}$. bonariensis - one proven to be resistant and one susceptible to glyphosate. In the center of the experimental unit, three seeds of the $C$. bonariensis biotype considered for treatment - resistant (R) or susceptible (S) - were sown, with the plant being surrounded by $O$ (no competition), 1, 2, 3, 4, or 5 plants of the opposite biotype. The susceptible biotype presented a higher tolerance to competition with plants of the opposite biotype regarding the physiological characteristics evaluated. The resistant biotype of $\mathbf{C}$. bonariensis has a physiological disadvantage compared to the susceptible one and, therefore, less potential for adaptability in the absence of the selection factor-the herbicide glyphosate.
\end{abstract}

Keywords: photosynthesis, transpiration, resistance, ecological adaptability.

Recebido para publicação em 18.2.2013 e aprovado em 19.5.2013.

2 Universidade Federal da Fronteira Sul, Campus Erechim-RS, Brasil, <galonleandro@ig.com.br>; ${ }^{3}$ Bolsista PNPD, UFVJM, Diamantina-MG, Brasil; ${ }^{4}$ Embrapa Agropecuária Oeste - CPAO, Dourados-MS, Brasil; ${ }^{5}$ Universidade Federal de Viçosa, ViçosaMG, Brasil; ${ }^{6}$ Embrapa Milho e Sorgo, Sete Lagoas-MG, Brasil; ${ }^{7}$ Universidade Estadual de Montes Claros, Janaúba-MG, Brasil; ${ }^{8}$ Embrapa Trigo, Passo Fundo-RS, Brasil. 


\section{INTRODUÇÃO}

A buva (Conyza bonariensis), originária dos Estados Unidos (Weaver et al., 2001), pertence à família Asteraceae e tem ciclo de desenvolvimento anual. É uma espécie extremamente prolífica, podendo produzir até 200.000 sementes viáveis por planta, estabelecendo-se em diversas condições climáticas. São plantas que apresentam boa adaptabilidade em sistemas conservacionistas do solo, como o plantio direto, o cultivo mínimo e as áreas de fruticultura que adotam o manejo integrado de produção (Bhowmik \& Bekech, 1993). A característica de autopolinização da espécie, aliada à grande produção de sementes facilmente dispersáveis, são fatores que contribuem para a boa adaptabilidade ecológica, para a sobrevivência de biótipos resistentes de buva e para as altas infestações nos sistemas conservacionistas (Thebaud et al., 1996).

O glyphosate pertence ao grupo dos herbicidas inibidores da síntese de aminoácidos que contêm o $\mathrm{N}$-(phosphonomethyl) glycina como ingrediente ativo. Após a absorção pelas plantas, é prontamente translocado, junto com fotossintatos, dos pontos de aplicação, situados nas folhas, até drenos distantes. Em plantas suscetiveis, o glyphosate atua inibindo a atividade da enzima plastídica sintase do 5-enolpiruvilshiquimato-3-fosfato (EPSPs), responsável pela reação que condensa shiquimato-3-fosfato e fosfoenolpiruvato em 5-enolpiruvilshiquimato-3-fosfato (EPSP) e fosfato inorgânico $(\mathrm{Pi})$, na etapa pré-corismato da rota do shiquimato (Shaner \& Bridges, 2003). A rota do shiquimato é ausente em animais, mas apresenta fundamental importância no metabolismo de plantas, fungos e bactérias, pois atua na biossintese dos aminoácidos aromáticos essenciais fenilalanina, tirosina e triptofano, além de outros compostos secundários importantes, como auxina e aleloquímicos (Hinchee et al., 1993). Estimase que mais de $20 \%$ de todo o carbono fixado pela fotossintese passe por essa rota, destinando-se à sintese dos aminoácidos aromáticos (Devine et al., 1993).

Quanto à capacidade competitiva dos biótipos resistentes em relação aos suscetiveis - o que muitas vezes determina a proliferação do biótipo na ausência do agente selecionador, a capacidade de extração e acúmulo de nutrientes pelas plantas, bem como o desempenho fisiológico, podem ser fatores importantes na capacidade competitiva dos biótipos. A competição é a luta que se estabelece entre a cultura e as plantas de outras espécies ou entre biótipos da mesma espécie existentes em um local, principalmente por água, luz, nutrientes e espaço (Radosevich et al., 2007). Estudos preliminares realizados por Ferreira et al. (2006) evidenciaram que o biótipo resistente de azevém que ocorre na região sul do país possui menor capacidade competitiva do que o biótipo suscetivel ao glyphosate. Essa capacidade competitiva de uma planta sobre outra afeta negativamente a quantidade e a qualidade da produção, bem como a eficiência de aproveitamento dos recursos do ambiente. As diferenças na habilidade competitiva entre biótipos normalmente estão relacionadas às características fisiológicas, associadas ao uso da água e da radiação solar pelas espécies vegetais (Sinclair et al., 1975; Melo et al., 2006).

Mutações genéticas ocorrem frequentemente na natureza em taxas variáveis, mas estima-se que em torno de $1 \times 10^{-6}$ plantas sofram mutação genética (Silva et al., 2007). A maioria dessas mutações é altamente deletéria, e a planta acaba não sobrevivendo; algumas, no entanto, não são letais e podem conferir à planta uma característica que torne possivel sua sobrevivência a um estresse antes letal (Silva et al., 2007). Essas alterações podem ainda ocasionar modificações no status nutricional das plantas cultivadas e, consequentemente, afetar a produtividade destas. Trabalho desenvolvido com as culturas de arroz e mostarda por Mishra \& Kurchana (2001) evidenciaram alterações dos teores de macronutrientes em tecidos foliares devido à aplicação de herbicidas. Também Carolus et al. (1971) aplicaram vários herbicidas em ervilhas e encontraram alteração nos teores de nutrientes, com variação mínima de peso de matéria seca. O uso de atrazine na cultura do amendoim proporcionou aumento nos teores de algumas formas de nitrogênio (Eastin \& Davies, 1967). A aplicação de glyphosate para controle de gramíneas em áreas de cultivo de pínus, ao se estudar a competição entre a 
cultura e as plantas daninhas, aumentou em $31 \%$ a concentração foliar de potássio (Sword et al., 1998). No entanto, são escassos os trabalhos encontrados na literatura que buscam determinar a habilidade competitiva entre biótipos resistentes e suscetiveis a herbicidas e a influência da competição em características relacionadas à fisiologia das plantas (Concenço et al., 2008, 2009).

Dessa forma, objetivou-se com este trabalho verificar o efeito da competição nas características fisiológicas de biótipos de C. bonariensis suscetivel e resistente ao herbicida glyphosate.

\section{MATERIAL E MÉTODOS}

O experimento foi instalado em ambiente protegido, mantido sob temperatura entre 22 e $27^{\circ} \mathrm{C}$ e iluminação natural. As unidades experimentais constaram de vasos plásticos com capacidade para $10 \mathrm{~L}$, contendo Latossolo Vermelho-Amarelo, corrigido quanto à fertilidade, de acordo com a análise química.

Os tratamentos constaram de plantas de dois biótipos de C. bonariensis - um comprovadamente resistente e um suscetivel ao glyphosate. No centro da unidade experimental foram semeadas três sementes do biótipo de Conyza bonariensis considerado como o tratamento: resistente (R) ou suscetivel (S). Na parte externa da unidade experimental, próximo à borda, foram semeadas dez sementes do biótipo oposto ao semeado no centro da unidade experimental.

Quarenta e cinco dias após a emergência dos biótipos, foi efetuado o desbaste, deixandose apenas uma planta no centro da unidade experimental e número variável de plantas do biótipo oposto $(0,1,2,3,4$ ou 5 plantas por vaso), de acordo com o tratamento, o que equivaleu a $18,38,56,75$ e 94 plantas $\mathrm{m}^{-2}$. A área do biótipo central da unidade experimental foi delimitada com cilindro com $5 \mathrm{~cm}$ de diâmetro e $2 \mathrm{~cm}$ de profundidade, aberto em ambas as extremidades, para facilitar a posterior identificação da planta central. O cilindro foi inserido no solo, com a borda superior rente à superficie, permitindo total desenvolvimento de raízes e da parte aérea da planta e plena competição por água, luz e nutrientes com as plantas da periferia.
O delineamento experimental utilizado foi o completamente casualizado, com os tratamentos dispostos em esquema fatorial $2 \times 6$, com três repetições. As unidades experimentais foram mantidas equidistantes, de forma que a área de superfície disponível para o desenvolvimento das plantas correspondesse à área da unidade experimental. Aos 50 dias após a emergência (DAE) foram realizadas as avaliações, no terço médio da primeira folha completamente expandida da planta central de C. bonariensis, em cada unidade experimental. As plantas nas extremidades dos vasos foram utilizadas somente como impositoras de competição, não sendo avaliadas. Foi utilizado um analisador de gases no infravermelho (IRGA), marca ADC, modelo LCA 4 (Analytical Development Co. Ltd, Hoddesdon, UK), em casa de vegetação aberta, permitindo livre circulação do ar. Cada bloco foi avaliado em um dia, entre 7 e 9 horas da manhã, de forma que mantivesse as condições ambientais homogêneas durante a avaliação de cada bloco.

As variáveis avaliadas foram consumo de $\mathrm{CO}_{2}$ no período de avaliação $\left(\Delta \mathrm{C}-\mu \mathrm{mol} \mathrm{mol}^{-1}\right)$, concentração de carbono interno no mesofilo foliar ( $\left.\mathrm{Ci}-\mu \mathrm{mol} \mathrm{mol}^{-1}\right)$, condutância estomática de vapores de água através dos estômatos (Gs -

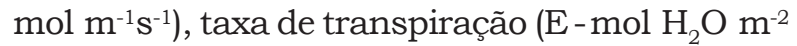
$\mathrm{s}^{-1}$ ) e taxa fotossintética (A - $\mu \mathrm{mol} \mathrm{m}^{-2} \mathrm{~s}^{-1}$ ), sendo calculada ainda a eficiência fisiológica do uso da água (WUE - mol CO $\mathrm{mol} \mathrm{H}_{2} \mathrm{O}^{-1}$ ) pela relação entre quantidade de $\mathrm{CO}_{2}$ fixado pela fotossintese e quantidade de água transpirada no mesmo intervalo de tempo.

Os dados foram submetidos à análise de variância pelo teste $\mathrm{F} \mathrm{e}$, quando significativos, efetuaram-se análises de regressão. Os testes foram efetuados a $5 \%$ de probabilidade.

\section{RESULTADOS E DISCUSSÃO}

Observou-se bom ajuste $(\mathrm{p}<0,001 \mathrm{e}$ $\mathrm{p}<0,005)$ entre as características fisiológicas avaliadas e as densidades dos biótipos estudados, representado por modelos lineares.

$\mathrm{O}$ consumo de $\mathrm{CO}_{2}(\Delta \mathrm{C})$ apresentou tendência de queda com o acréscimo da população do biótipo oposto para os dois biótipos avaliados; no entanto, o suscetível mostrou redução menos acentuada do $\Delta \mathrm{C}$ em relação ao resistente com o incremento da densidade do 
biótipo oposto alocado na periferia do vaso (Figura 1A).

Os resultados demonstram, para a concentração do carbono interno (Ci), que o biótipo resistente apresentou em todas as densidades estudadas maiores concentrações de $\mathrm{CO}_{2}$ no mesofilo foliar, comparado aos valores observados para o biótipo suscetivel (Figura 1B). Vale ressaltar que as variáveis $\Delta \mathrm{C}$ e Ci têm relação inversa, isto é, quanto maior o $\Delta \mathrm{C}$, maior o consumo de $\mathrm{CO}_{2}$ usado na fotossíntese, o que reduz o Ci. Assim, com o incremento da competição, os dois biótipos estudados apresentaram tendência de redução do $\Delta \mathrm{C}$ e incremento do $\mathrm{Ci}$; esse comportamento pode ser considerado como efeito da competição, que foi menos drástico para o biótipo suscetivel, principalmente nas densidades intermediárias do competidor.

Ressalta-se ainda que, à medida que se aumentou a densidade de plantas, tanto do biótipo resistente quanto do suscetível, o $\mathrm{Ci}$ (Figura 1B) aumentou proporcionalmente. O Ci é considerado uma variável fisiológica influenciada por fatores ambientais, como disponibilidade hídrica, de luz e energia, entre outros. O incremento no Ci observado no biótipo resistente, quando em competição com plantas mais vigorosas, pode indicar menor capacidade deste em competir por luz ou por $\mathrm{CO}_{2}$, comparado à das plantas do biótipo suscetível (Concenço et al., 2008).

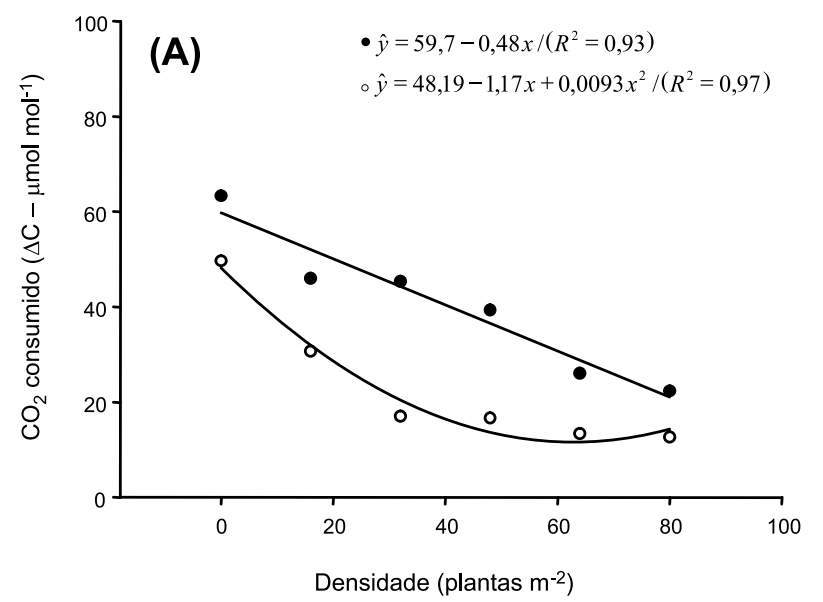

O biótipo suscetível de C. bonariensis apresentou elevada taxa transpiratória (E) nas menores densidades, no entanto, a partir da densidade de 48 plantas $\mathrm{m}^{-2}$, a $\mathrm{E}$ inicia uma tendência de queda (Figura 2A). Para o biótipo resistente, observou-se redução gradual da $\mathrm{E}$, e nas maiores densidades houve semelhanças para os dois biótipos. Isso pode indicar a existência de uma taxa basal de transpiração para as plantas de buva, quando estas se encontram em condições ambientais desfavoráveis. Enquanto o biótipo suscetível consegue responder melhor à maior disponibilidade de recursos do ambiente, plantas do biótipo resistente, mesmo em condições favoráveis, apresentam taxa transpiratória próxima à taxa basal teórica. Concenço et al. (2007), ao trabalharem com biótipos resistentes e suscetíveis de azevém, verificaram que a taxa de transpiração (E) não foi alterada quando uma planta isolada competia com um grupo de plantas do biótipo oposto para os dois biótipos avaliados, o que pode indicar que (i) algumas espécies não possuem uma taxa de transpiração basal, (ii) esta taxa existe, mas é muito próxima ao ótimo observado para a espécie, o que acarreta não significância estatística, ou (iii) os níveis de competição no estudo de Concenço et al. (2007) não foram altos o suficiente para reduzir os processos fisiológicos às suas taxas basais.

$\mathrm{Na}$ densidade inicial, em que foi mantida uma planta de $C$. bonariensis isolada no centro

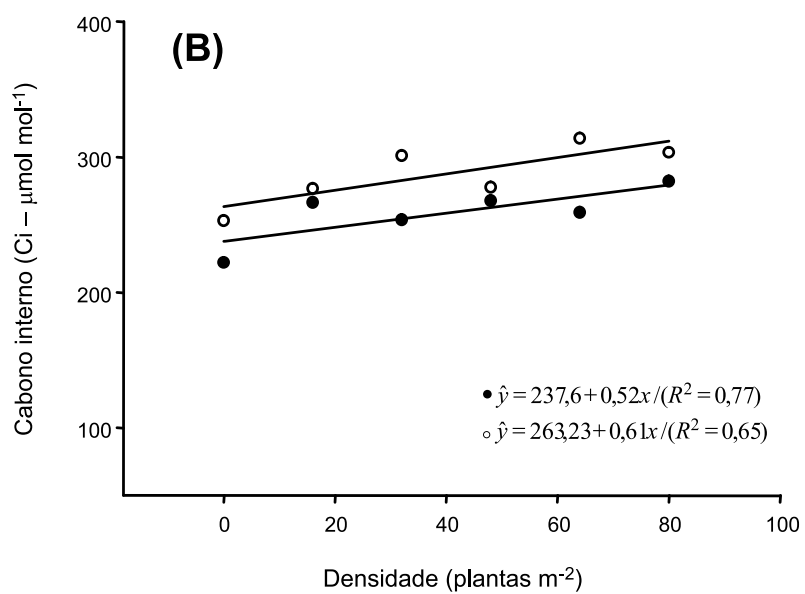

Figura 1 - $\mathrm{CO}_{2}$ consumido $-\Delta \mathrm{C}(\mathrm{A})$ e carbono interno - Ci (B) de biótipos suscetíveis $(\bullet)$ e resistentes (o) de C. bonariensis em competição com diferentes densidades do biótipo oposto. 

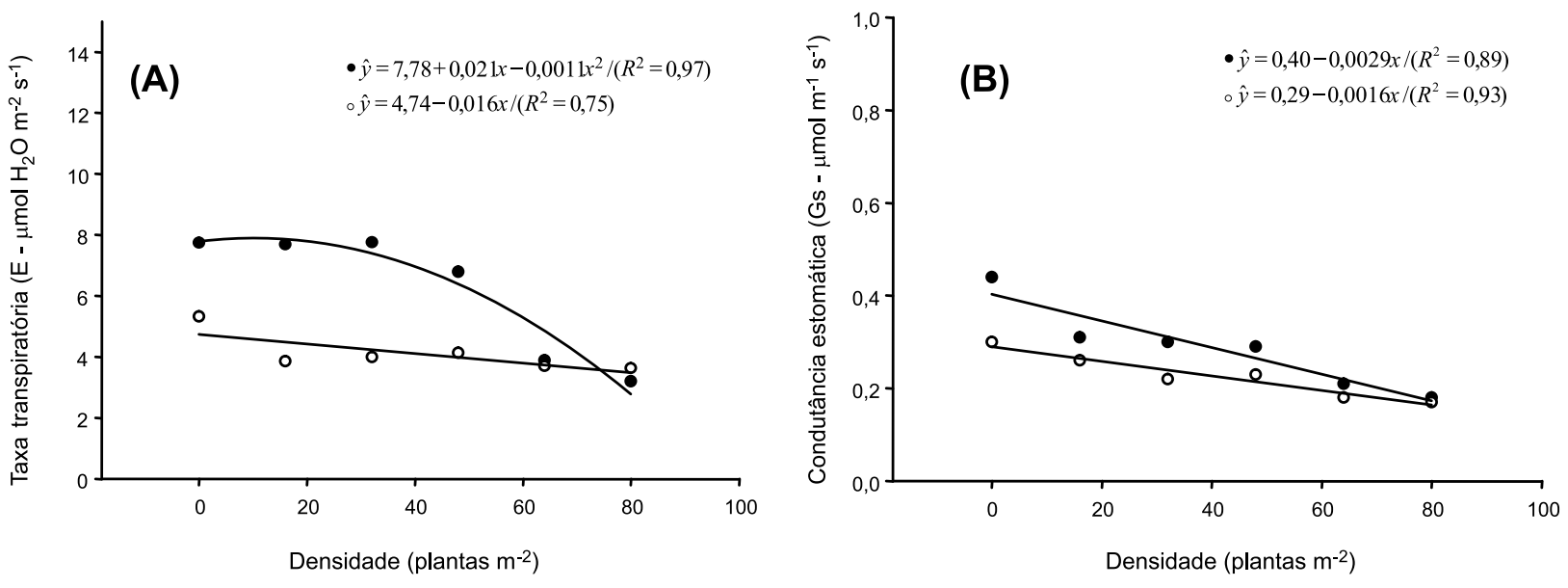

Figura 2 - Taxa transpiratória - E (A) e condutância estomática - Gs (B) de biótipos suscetíveis (•) e resistentes (o) de C. bonariensis em competição com diferentes densidades do biótipo oposto.

do vaso (ausência de competição), o biótipo suscetivel mostrou maior condutância estomática (Gs) em relação ao resistente. Para os dois biótipos, constatou-se decréscimo da Gs com o aumento da população de plantas do biótipo oposto. Convém destacar que o biótipo suscetível apresentou maior redução da Gs; na densidade de 80 plantas $\mathrm{m}^{-2}$, a Gs foi semelhante para os dois biótipos avaliados.

O declínio de transpiração está associado ao fechamento dos estômatos, e variações na abertura estomática causam alterações no potencial hídrico, por atuarem sobre a $\mathrm{E}$ (Brodribb \& Holbrook, 2003). Consequentemente, espera-se redução similar na E com redução na Gs visando evitar o estresse hídrico (Cochard et al., 2002), o que também ocorre quando a planta está fechando os estômatos, devido aos níveis de luz estarem abaixo da radiação fotossinteticamente ativa. Concenço et al. (2007) observaram que a condutância estomática dos vapores de água (Gs) não se alterou com o aumento da densidade de plantas do biótipo oposto de azevém resistente ao glyphosate, tanto para o suscetivel como para o resistente, o que pode indicar baixos niveis de competição para aquela espécie ou, então, que nas condições estudadas ambos os biótipos apresentavam valores de Gs próximos aos dos basais. Além disso, outros fatores que influenciam a condutância foliar podem ter ocorrido em níveis suficientes para impactar as avaliações.
A condutância foliar é composta em pequena parte pela condutância cuticular da epiderme e, quando os estômatos estão abertos, pela Gs, que é controlada pelas célulasguarda dos estômatos. Assim, a Gs é proporcional ao número, tamanho e diâmetro da abertura dos estômatos, características que dependem de outros fatores endógenos e ambientais (Brodribb \& Holbrook, 2003). A água só é perdida por transpiração enquanto os estômatos estão abertos. O controle da abertura e o fechamento dos estômatos dependem de uma série de fatores, como radiação solar, nivel de $\mathrm{CO}_{2}$ no mesofilo, umidade relativa (déficit de pressão de vapor do ar), potencial hídrico e outros de menor magnitude, como vento, substâncias de crescimento e ritmos endógenos próprios de cada espécie.

A taxa fotossintética (A) apresentou redução gradual nos dois biótipos estudados; a taxa de redução foi muito próxima para ambos os biótipos, embora o biótipo resistente tenha apresentado maiores taxas de redução em função do aumento na competição. A fotossintese e, consequentemente, a respiração dependem de constante fluxo de $\mathrm{CO}_{2} \mathrm{e}$ $\mathrm{O}_{2}$ entrando e saindo da célula; esse fluxo livre é função da concentração dos dois gases nos espaços intercelulares, que por sua vez dependem da abertura estomática, controladora majoritária do fluxo de $\mathrm{CO}_{2}$ e $\mathrm{O}_{2}$ (Taylor Jr. \& Gunderson, 1986; Messinger et al., 2006). Esta, por sua vez, é em grande parte controlada 
pela turgescência tanto das células-guarda (que controlam a abertura dos estômatos) como das células epidérmicas dos estômatos. Um potencial hídrico baixo, que induz o fechamento do estômato e reduz a condutância foliar, inibe a fotossintese e também a respiração (Attridge, 1990). Assim, existe uma relação direta entre A e E; dessa forma, o aumento da densidade de plantas pode ter influenciado a disponibilidade de água para as plantas cultivadas em competição, provocando o fechamento dos estômatos, o que reduziu a condutância estomática, a taxa transpiratória e, por conseguinte, a taxa fotossintética.

O biótipo resistente demonstra ser mais sensivel à competição em relação ao suscetível, com base nas características fisiológicas avaliadas. Dessa forma, o biótipo suscetível pode apresentar maior adaptação ecológica comparado ao resistente. Segundo Christoffoleti (1997), entende-se por adaptabilidade ecológica a capacidade que um biótipo possui, dentro de uma população de plantas daninhas, de manter ou aumentar sua proporção ao longo do tempo. Isso é válido, no entanto, somente na ausência do fator de seleção do biótipo resistente - o herbicida glyphosate. Em lavouras com uso intenso desse herbicida o biótipo resistente tende a predominar, o que provavelmente não ocorrerá em ambientes naturais na ausência do agente selecionador. Esse fato é confirmado por Saari et al. (1994), os quais afirmam que os biótipos resistentes que apresentam menor adaptação ecológica podem se tornar predominantes devido à eliminação das plantas sensiveis e que, em condições de seleção natural, biótipos com maior adaptação ecológica apresentam, em média, maior produção que biótipos menos adaptados.

A maioria dos estudos relacionados à comparação da habilidade competitiva entre os biótipos resistente e suscetivel de plantas daninhas tem sido realizada com espécies pertencentes à classe Magnoliopsida. Essas pesquisas têm demonstrado prejuízo para o biótipo resistente em relação ao suscetivel (LeBaron \& Gressel, 1982; Ferreira et al., 2008; Concenço et al., 2009). Biótipos de Amaranthus retroflexus (Radosevich, 1977) e Chenopodium album (Parks et al., 1996), sensiveis às triazinas, apresentaram maior área foliar, altura e produção de sementes que os biótipos resistentes. A menor capacidade competitiva, o crescimento e a produtividade de plantas resistentes a triazinas podem estar relacionados com a sua capacidade fotossintética limitada (Stowe \& Holt, 1988). Entretanto, em campo, tem-se observado o domínio dos biótipos resistentes sobre os suscetiveis, embora estes apresentem normalmente menor adaptação ecológica, devido à presença do agente selecionador - o herbicida.

Ferreira et al. (2008), ao trabalharem com biótipos de azevém resistente e suscetivel ao glyphosate, observaram diferenças na capacidade competitiva entre os biótipos resistente e suscetivel ao estudarem variáveis como altura de planta, massa seca e área foliar. No mesmo estudo, o biótipo suscetível apresentou menor tendência de redução dessas variáveis com o incremento da intensidade de competição. Moreira et al. (2010) observaram que o biótipo de C. canadensis resistente ao herbicida glyphosate demonstrou crescimento mais lento e menor acúmulo de área foliar e de massa seca que o suscetivel, e o crescimento absoluto do biótipo suscetível foi superior ao do resistente.

A translocação diferencial do glyphosate nos biótipos resistentes tem sido considerada o principal mecanismo de resistência das plantas, o que sugere que o menor crescimento desses biótipos seja consequência da possivel diferença na distribuição dos fotoassimilados. Ferreira et al. (2008) verificaram que o biótipo resistente de $C$. bonariensis apresentou menor translocação do glyphosate em relação ao biótipo suscetível.

Denis \& Delrot (2006) afirmam que uma menor eficiência na absorção de fósforo por parte dos biótipos resistentes pode levar à menor adaptabilidade ecológica por parte destes, influenciando indiretamente variados processos fisiológicos da planta, considerando que o fosfóro assume importantes funções nos tecidos vegetais, como componente de fosfatos, açúcares, ácidos nucleicos, nucleotídeos, coenzimas, fosfolipídios e ácido fitico, e tem papel central em reações que envolvem ATP (Taiz \& Zeiger, 2009). Assim, a menor eficiência do uso da água (EUA) observada para o biótipo suscetivel em altas 

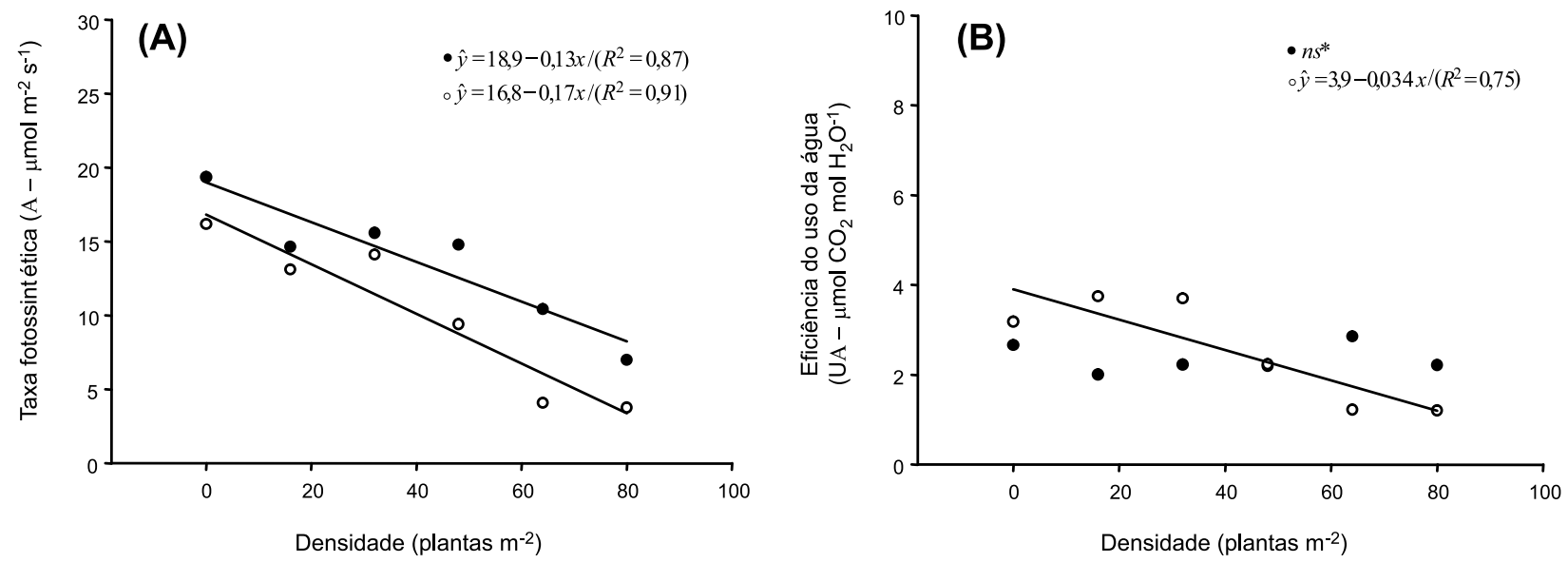

Figura 3 - Taxa fotossintética - A (A) e eficiência no uso da água - UA (B) de biótipos suscetíveis (•) e resistentes (o) de C. bonariensis em competição com diferentes densidades do biótipo oposto.

intensidades de competição, em contraponto à vantagem para esse biótipo nas menores densidades do competidor (Figura 3B), pode indicar que, embora os estômatos estejam abertos, permitindo a entrada de $\mathrm{CO}_{2}$ concomitante à perda de água, o processo fotossintético pode estar sendo prejudicado por algum outro processo. Isso resulta em menor eficiência de uso de água pelo biótipo.

O biótipo suscetível de buva é mais tolerante à competição em relação às características fisiológicas avaliadas. Assim, propõe-se que o biótipo de Conyza bonariensis resistente ao glyphosate pode apresentar desvantagens fisiológicas em relação ao suscetível, as quais possivelmente estão relacionadas ao mecanismo de resistência ao herbicida.

\section{AGRADECIMENTOS}

Ao Conselho Nacional de Desenvolvimento Científico e Tecnológico (CNPq), à Coordenação de Aperfeiçoamento de Pessoal de Nivel Superior (CAPES) e à Fundação de Amparo à Pesquisa do Estado de Minas Gerais (FAPEMIG), pelo apoio financeiro e pelas bolsas concedidas.

\section{LITERATURA CITADA}

ATTRIDGE, T. H. The natural light environment. In: ATTRIDGE, T. H. (Ed.). Light and plant responses. London: Edward Arnold, 1990. p. 1-5.
BHOWMIK, P. C.; BEKECH, M. M. Horseweed (Conyza canadensis) seed production, emergence and distribuition in no-tillage and conventional-tillage corn (Zea mays).

Agronomy, v. 1, n. 1, p. 67-71, 1993.

BRODRIBB, T. J.; HOLBROOK, N. M. Stomatal closure during leaf dehydration, correlation with other leaf physiological traits. Plant Physiol., v. 132, n. 4, p. 2166-2173, 2003.

CAROLUS, R. L. et al. Effects of soil applied herbicides and caucium on mineral composition of peas (Pisum nativum L.). Hortic. Sci., v. 26, n. 1, p. 278-283, 1971.

CHRISTOFFOLETI, P. J. Resistência de plantas daninhas aos herbicidas. In: SIMPÓSIO SOBRE HERBICIDAS E PLANTAS DANINHAS, 1., 1997, Dourados. Palestras... Dourados: Embrapa, 1997. p. 75-94.

COCHARD, H. et al. Unraveling the effects of plant hydraulics on stomatal closure during water stress in walnut. Plant Physiol., v. 128, n. 1, p. 282-290, 2002.

CONCENÇO, G. et al. Uso da água em biótipos de azevém (Lolium multiflorum) em condição de competição.

Planta Daninha, v. 25, n. 3, p. 449-455, 2007.

CONCENÇO, G. et al. Eficiência fotossintética de biótipos de azevém em condição de competição. Planta Daninha, v. 19, n. 2, p. 247-253, 2008.

CONCENÇO, G. et al. Uso da água por plantas de arroz em competição com biótipos de Echinochloa crusgalli resistente e suscetível ao herbicida quinclorac. Planta Daninha, v. 27, n. 2, p. 249-256, 2009.

Planta Daninha, Viçosa-MG, v. 31, n. 4, p. 859-866, 2013 
DENIS, M. H.; DELROT, S. Carrier-mediated uptake of glyphosate in broad (Vicia faba) via a phosphate transporter. Physiol. Plant., v. 87, n. 4, p. 569-575, 2006.

DEVINE, M. et al. Inhibition of aromatic amino acid synthesis. In: DEVINE, M. et al. Physiology herbicide action. Englewood Cliffs: Prentice Hall, 1993. p. 252-263.

EASTIN, E. F.; DAVIES, D. E. Effects os atrazine and hidroxitriazine on nitrogen metabolism of selected species. Weed Sci., v. 15, n. 1, p. 306-309, 1967.

FERREIRA, E. A. et al. Translocação de glyphosate em biótipos de azevém (Lolium multiflorum). Planta Daninha, v. 24, n. 2, p. 365-370, 2006.

FERREIRA, E. A. et al. Glyphosate translocation in hairy fleabane (Conyza bonariensis) biotypes. Planta Daninha, v. 26, n. 3, p. 637-643, 2008.

HINCHEE, M. A. W. et al. Herbicide-tolerant crops. In: KUNG, S.; WU, R. (Eds.). Transgenic plants. San Diego: Academic Press, 1993. p. 243-263.

LeBARON, H. M.; GRESSEL, J. Summary of accomplishments, conclusions, and future needs. In: LeBARON, H. M.; GRESSEL, J. (Ed.) Herbicide resitance en plants. New York: John Wiley \& Sons, 1982. p. 349-362.

MELO, P. T. B. S. et al. Comportamento de populações de arroz irrigado em função das proporções de plantas originadas de sementes de alta e baixa qualidade fisiológica. R. Bras. Agroci., v. 12, n. 1, p. 37-43, 2006.

MESSINGER, S. M. et al. Evidence for involvement of photosynthetic processes in the stomatal response to $\mathrm{CO}_{2}$. Plant Physiol., v. 140, n. 2, p. 771-778, 2006.

MISHRA, J. S.; KURCHANIA, S. P. Nutrient content in mustard and associated weeds as influenced by nitrogen levels, planting geometry and weed control methods. Indian J. Plant Physiol., v. 6, n. 4, p. 386-389, 2001.

MOREIRA, M. S. et al. Crescimento diferencial de biótipos de Conyza spp. resistente e suscetível ao herbicida glyphosate. Bragantia, v. 69, n. 3, p. 591-598, 2010.

PARKS, R. J. et al. Herbicide susceptibility and biological fitness of triazine-resistant and susceptible common lambsquarters (Chenopodium album). Weed Sci., v. 44, n. 3, p. 517-522, 1996.
RADOSEVICH, S. R. Mechanism of atrazine resistance in lambsquarters and pigweed. Weed Sci., v. 25, n. 4, p. 316-318, 1977.

RADOSEVICH, S.; HOLT, J.; GHERSA, C. Ecology of weeds and invasive plants: relationship to agriculture and natural resource management. New York: Wiley, 2007. 454 p.

SAARI, L. L.; COTTERMAN, J. C.; THILL, D. C. Resistance to acetolactate synthase inhibiting herbicides. In: POWLES, S. B.; HOLTUM, J. A. M. Herbicide resistance in plants: biology and biochemistry. Boca Raton: 1994. p. 83-139.

SHANER, D.; BRIDGES, D. Inhibitors of aromatic amino acid biosyntesis (glyphosate). In: SHANER, D.; BRIDGES, D. Herbicide action course. West Lafayette: Purdue University, 2003. p. 514-529.

SILVA, A. A. et al. Herbicidas: resistência de plantas. In: SILVA, A. A.; SILVA, J. F. Tópicos em manejo de plantas daninhas. Viçosa, MG: Sociedade Brasileira de Plantas Daninhas, 2007. 367 p.

SINCLAIR, T. R. et al. Water use efficiency of field-grown maize during moisture stress. Plant Physiol., v. 56, n. 2, p. 245-249, 1975.

STOWE, A. E.; HOLT, J. S. Comparison of triazine-resistant and -susceptible biotypes of Senecio vulgaris and their F1 hybrids. Plant Physiol., v. 87, n. 1, p. 183-189, 1988.

SWORD, M. A. et al. Establishment treatments affect relationships among nutrition, productivity and competing vegetation of loblolly pine saplings on a Gulf Coastal Plain site. Forest Ecol. Manag., v. 105, n. 2, p. 175-188, 1998.

TAYLOR Jr., G. E.; GUNDERSON, C. A. The response of foliar gas exchange to exogenously applied ethylene. Plant Physiol., v. 82, n. 3, p. 653-657, 1986.

TAIZ, L.; ZEIGER, E. Fisiologia vegetal. 4.ed. São Paulo: Artmed, 2009. 719 p.

THEBAUD, C.; ABBOTT, R. J. Characterization of invasive Conyza species (Asteraceae) in Europe: quantitative trait and isoenzyme analysis. American Journal of Botany, v. 82, n. 3, p. 360-368, 1995.

WEAVER, S. E. The biology of Canadian weeds, Conyza canadensis. Can. J. Plant Sci., v. 81, n. 4, p. 867-875, 2001. 